\title{
A Comparative Study between Propofol and Dexmedetomidine for Hypotensive Anesthesia in ENT Surgeries in Indian Phenotype
}

\author{
Rajashree Deelip Godbole ${ }^{1}$, Brishnik Bhattacharya ${ }^{2}$, Tehzeebunnisa Saleem ${ }^{3}$, Siddhesh Patil ${ }^{4}$, Rajeshkumar Resoju ${ }^{5}$, \\ Priyanka Patil ${ }^{6}$
}

\begin{abstract}
Objective: To compare the efficacy and safety of dexmedetomidine and propofol for hypotensive anesthesia in ENT surgeries in Indian phenotype. Materials and methods: A prospective, randomized, comparative study. The study population of 72 patients of Indian phenotype were randomly taken from random number table and divided into two groups with 36 patients in each group. Group $\mathrm{D}=$ dexmedetomidine (dexmedetomidine loading dose of $1 \mu \mathrm{g} / \mathrm{kg}$ dexmedetomidine diluted in $10 \mathrm{~mL} 0.9 \%$ saline infused over 10 minutes before induction of anesthesia, followed by infusion of $0.2-0.7 \mu \mathrm{g} / \mathrm{kg} / \mathrm{hour}$ ). Group P = propofol group (maintenance dose 100-150 $\mu \mathrm{g} / \mathrm{kg} / \mathrm{hour}$ ). The infusions were titrated to maintain mean arterial pressure (MAP) between 55 and $65 \mathrm{~mm} \mathrm{Hg}$ and hemodynamic stability.

Results: In our study, we did not have hypotension or bradycardia that needed treatment. The heart rate and blood pressure were on the lower side in group D compared to group P. The awakening time was significantly short in group D than group P. The average doses of dexmedetomidine around $0.2 \pm 0.04 \mu \mathrm{g} / \mathrm{kg} / \mathrm{hour}$ and propofol around $140 \pm 41 \mu \mathrm{g} / \mathrm{kg} / \mathrm{hour}$ which are at the lowest end of the recommended doses of $0.2-0.7 \mu \mathrm{g} /$ $\mathrm{kg} / \mathrm{hour}$ and $100-300 \mu \mathrm{g} / \mathrm{kg} /$ hour for hypotensive anesthesia. These low doses may be the cause of no complications in the Indian population.

Conclusion: In our comparative study done in Indian population, we observed that both dexmedetomidine and propofol have achieved desired hypotension in patients undergoing ENT surgeries to improve the operative field visibility by reducing the blood loss. Although achieved reduction in MAP was statistically nonsignificant, MAP was lower in dexmedetomidine than propofol. A significantly higher Ramsay sedation score in propofol group is suggestive of greater degree of sedation than dexmedetomidine, making it a better choice for hypotensive anesthesia. Keywords: Dexmedetomidine, ENT surgeries, Hypotensive anesthesia, Propofol.

The Journal of Medical Sciences (2019): 10.5005/jp-journals-10045-00132
\end{abstract}

\section{INTRODUCTION}

Controlled hypotension during surgery - hypotensive anesthesiais widely practiced and considered suitable for various surgeries including maxillofacial surgeries. Hypotensive anesthesia limits the blood loss during surgery and facilitates speed of surgery by making the surgical field bloodless. Maintaining normal blood pressure (BP) during any surgery is an index of skillful anesthesia, as the organ perfusion is preserved between the normal BP limits. Achieving optimum hypotension is a skill, as excess lowering of BP may be hazardous due to the reduced perfusion to essential organs such as brain, heart, and kidneys. Reduction in mean arterial pressure (MAP) by $30 \%$ is considered adequate. This results in systolic BP of $80-90 \mathrm{~mm} \mathrm{Hg}$ and MAP of 50-65 mm Hg. Surgeries of ear, nose, and throat (ENT) pose great challenges for surgeons as well as for the anesthesiologists due to dense vascularity of the region, repeated infections leading to fibrosis, increased blood loss during surgery, and limited operative field. Nowadays, endoscopic sinus surgeries and microscopic surgeries are demanding controlled hypotensive anesthesia, and so it is the need of the time.

For achieving controlled hypotension, certain characteristics are desired in the agent used for the purpose. The ideal agent should have ease of administration, short onset time, an effect that disappears quickly on discontinuation, rapid elimination without toxic metabolites, negligible or no effects on vital organs, and predictable and dose-dependent effects. ${ }^{1,2}$

Various agents such as inhalational anesthetics, $\beta$-blockers, nitroglycerine, sodium nitroprusside, and magnesium sulfate are
${ }^{1-6}$ Department of Anaesthesiology, King Edward Memorial Hospital, Pune, Maharashtra, India

Corresponding Author: Rajashree Deelip Godbole, Department of Anaesthesiology, King Edward Memorial Hospital, Pune, Maharashtra, India, Phone: +91 9822049748, e-mail: rajashree.godbole@gmail.com How to cite this article: Godbole RD, Bhattacharya B, Saleem T, et al. A Comparative Study between Propofol and Dexmedetomidine for Hypotensive Anesthesia in ENT Surgeries in Indian Phenotype. J Med Sci 2019;5(4):81-87.

Source of support: Nil

Conflict of interest: None

routinely used. Dexmedetomidine is a highly selective $a 2$ agonist. It acts on a2A and imidazoline type I receptors. Alpha-2 receptors regulate the autonomic nervous and cardiovascular systems. They are located in the blood vessels, where they cause vasoconstriction and in the sympathetic terminal where they inhibit norepinephrine release. This ultimately leads to fall in BP and heart rate (HR). Dexmedetomidine is equally useful for controlled hypotension. ${ }^{3}$ Dexmedetomidine has got inherent analgesic, sedative, and anesthetic-sparing properties that avoid use of multiple drugs., ${ }^{4,5}$ Dexmedetomidine exerts sedative and analgesic-sparing effect through central locus ceruleus and in the dorsal horn of the spinal cord. ${ }^{6}$

Propofol is an intravenous anesthetic agent useful for controlled hypotension. It is associated with positive influence on the inhibitory 
function of the neurotransmitter $\gamma$-aminobutyric acid (GABA) through GABA-A receptors. ${ }^{7,8}$ Propofol has negative inotropic effect through inhibition of sympathetic vasoconstrictor nerve activity. It has got anti-emetic, antipruritic, and anticonvulsant activity. Complete awakening without residual central nervous system effects has made it popular for day care surgery. The use of propofol infusion for deliberate hypotension is associated with improved quality of surgical field in functional endoscopic sinus surgery (FESS). ${ }^{9}$

In a randomized study in Iranian patients undergoing FESS by Moshiri et al., propofol and dexmedetomidine were reported to be equally effective in reduction of bleeding and achieving appropriate surgical field. ${ }^{10}$ Shah et al. and Rupa Kumari et al. reported similar outcomes with both agents in FESS in Indian population. ${ }^{11,12}$ Verma et al. reported that propofol was associated with greater requirement of rescue analgesia and poor patient satisfaction than dexmedetomidine in middle ear surgeries. ${ }^{13}$

We performed this comparative study to explore and understand the efficacy and safety of both agents for controlled hypotension in ENT surgeries and to find out the minimum effective dose of infusion for controlled hypotension in Indian population.

\section{Materials and Methods}

\section{Study Design}

A prospective, randomized, and comparative study.

\section{Study Population and Sample Size}

The study population of 72 patients of Indian phenotype were randomly taken from random number table and divided into two groups with 36 patients in each group.

- Group $D=$ dexmedetomidine (dexmedetomidine loading dose of $1 \mu \mathrm{g} / \mathrm{kg}$ dexmedetomidine diluted in $10 \mathrm{~mL} 0.9 \%$ saline infused over 10 minutes before induction of anesthesia, followed by continuous infusion of $0.2-0.7 \mu \mathrm{g} / \mathrm{kg} /$ hour)

- Group P = propofol group (maintenance dose 100-150 $\mu \mathrm{g} / \mathrm{kg} /$ hour)

\section{Inclusion Criteria}

Normal adult patients of either sex, age-group between 18 years and 55 years, and patients with ASA physical status I or II undergoing ENT surgeries.

\section{Exclusion Criteria}

Patients who are not willing to give consent for participation in the study; pregnant females; patients with hypertension, coronary artery diseases, and renal, hepatic, or cerebral insufficiency; patients taking $\beta$-blockers; patients with coagulopathies or receiving drugs influencing blood coagulation; and patients with known allergy to either drug.

\section{Methodology}

The data were collected in a pretested proforma meeting the objectives of the study after obtaining approval from the institutional ethical committee and informed written consent from the patient. The study population was divided into two groups as mentioned.

\section{Materials and Methods}

Surgical procedures included in this study are tympanoplasty, chronic suppurative otitis media, dacrocystitis, stapedectomy, FESS, recurrent polyposis, deviated nasal septum, myringoplasty, etc.

\section{Preoperative Assessment}

Preanesthetic evaluation was done on the evening before surgery, and written informed consent was taken and patient was kept nil orally 6 hours prior to surgery. On the day of the surgery, patients were connected to multiparameter monitor for monitoring pulse, $\mathrm{SpO}_{2}, \mathrm{ECG}, \mathrm{NIBP}, \mathrm{ETCO}_{2}$, and temperature in the operation theater. Intravenous line was secured with no. 20 intravenous cannula. Baseline BP and HR were recorded.

\section{Premedication}

All patients in both the groups were premedicated with Inj Midazolam 0.05 mg/kg IV, Inj Fentanyl 2 Mg/kg, IV, and ondansetron $0.1 \mathrm{mg} / \mathrm{kg}$ IV. Anesthesia was induced with Inj thiopentone $5 \mathrm{mg} /$ $\mathrm{kg}$ until loss of verbal response. Endotracheal intubation was facilitated with Inj.Vecuronium $0.1 \mathrm{mg} / \mathrm{kg}$ with suitable sized cuffed endotracheal tube. Anesthesia was maintained with oxygen, nitrous oxide, and sevoflurane $1 \%$ in all the patients. In group D, anesthesia was maintained with dexmedetomidine infusion starting with $0.2-0.7 \mu \mathrm{g} / \mathrm{kg} / \mathrm{hour}$ and in group P $150 \mu \mathrm{g} / \mathrm{kg} / \mathrm{hour}$ initially which was titrated to maintain MAP between 55 and $65 \mathrm{~mm} \mathrm{Hg}$ with stable hemodynamics. All the patients were put in $15^{\circ}-20^{\circ}$ head high position. The patients were covered with warm air blanket to maintain body temperature.

In both the groups, cotton pledgets soaked with epinephrine in a concentration of 1:80.000 was inserted into the nasal cavity and in-between the polyps to minimize blood loss. The infusion of hypotensive agent was stopped 10 minutes before end of the surgery, and patients were reversed with neostigmine and glycopyrrolate at the end with good respiratory efforts in all the cases. Extubation was done when the patients were awake and following commands.

\section{Parameters to be Observed}

Systolic BP, diastolic BP, MAP, and HR. Hemodynamics were recorded preoperatively (baseline) postinduction (after administration of hypotensive and anesthetic agent) every 5 minutes intraoperatively, 5 minutes, and 10 minutes after stoppage of hypotensive agents and lastly after recovery. Ramsey Sedation score was measured using the following scale at $\mathbf{3 0}$ minutes after tracheal extubation.

\section{Ramsay Sedation Score}

- Anxious, agitated, or restless

- Cooperative, oriented, and tranquil

- Responsive to commands

- Asleep, but with brisk response to light, glabellar tap, or loud auditory stimulus

- Asleep, sluggish response to glabellar tap, or auditory stimulus; and

- Asleep, no response. Patients will also be asked about recalling of intraoperative events or any sign of awareness.

\section{Statistical Methods}

Descriptive statistical analysis was carried out to explore the distributions of several characteristics of the cases studied. Results on categorical data are shown as $n$ (\% of cases), and the results on quantitative variables are shown as mean \pm standard deviation across two intervention groups. The statistical significance of difference in various qualitative responses was tested using chi-square test for independence of attributes or Fisher's exact probability test. For comparing quantitative variables across two 
intervention groups, independent sample $t$ test was used after confirming the underlying normality assumption. $p$ values $<0.05$ was considered to be statistically significant. The entire statistical analysis was performed using Statistical Package for Social Sciences (SPSS version 11.5, Chicago, IL) for MS Windows.

\section{Results}

Table 1 shows the HR at different time periods of assessments during surgery. Baseline HR in groups $D$ and $P$ was $86.89 \pm 12.09$ and $84.86 \pm$ 12.14 beats per minutes, respectively, with no statistically significant difference ( $p$ value $=0.480$ ). Thereafter, it did not differ significantly at different timelines of 5 minutes interval till 80 minutes. At 80 minutes $(p$ value $=0.043), 85$ minutes $(p$ value $=0.010)$,
90 minutes ( $p$ value $=0.027$ ), and 95 minutes ( $p$ value $=0.025), \mathrm{HR}$ was significantly higher in group $B$ than group $A$. At 110 minutes also, HR was significantly higher in group $B$ ( $p$ value $=0.024$ ).

Table 2 shows the means of MAP changes in two groups at different time periods during surgery. MAP was not significantly different from baseline to all time periods of assessment in two groups except at 95 minutes of surgery, where MAP was significantly higher in group $\mathrm{P}$ than $\mathrm{D}(77.11 \pm 11.16$ vs. $70.37 \pm 11.88, p$ value $=$ 0.030). At further time periods of assessment, there were no significant differences in DBP in two groups, although it was relatively on higher side in group $B$.

Average infusion rate was $12.11 \pm 3.46 \mu \mathrm{g} /$ hour in group $\mathrm{D}$, whereas it was $88.33 \pm 30.61 \mathrm{mg} /$ hour in group $\mathrm{P}$ as shown in Table 3.

Table 1: Comparison of heart rate in two groups at different timelines

\begin{tabular}{|c|c|c|c|c|}
\hline Timelines & $N$ group $D / P$ & Group D & Group P & $p$ value \\
\hline Baseline & $36 / 36$ & $86.89 \pm 12.09$ & $84.86 \pm 12.14$ & 0.480 \\
\hline 5 minutes & $36 / 36$ & $79.58 \pm 10.97$ & $83.22 \pm 13.73$ & 0.218 \\
\hline 10 minutes & $36 / 36$ & $74.97 \pm 12.88$ & $78.08 \pm 12.61$ & 0.304 \\
\hline 15 minutes & $36 / 36$ & $72.94 \pm 13.12$ & $75.69 \pm 13.47$ & 0.383 \\
\hline 20 minutes & $36 / 36$ & $71.56 \pm 10.76$ & $73.19 \pm 12.69$ & 0.557 \\
\hline 25 minutes & $36 / 36$ & $70.08 \pm 9.86$ & $71.44 \pm 11.42$ & 0.590 \\
\hline 30 minutes & $36 / 36$ & $68.06 \pm 8.95$ & $70.94 \pm 10.49$ & 0.213 \\
\hline 35 minutes & $36 / 36$ & $67.50 \pm 8.47$ & $69.72 \pm 9.93$ & 0.311 \\
\hline 40 minutes & $36 / 36$ & $66.31 \pm 8.68$ & $69.19 \pm 9.12$ & 0.173 \\
\hline 45 minutes & $36 / 36$ & $66.33 \pm 8.88$ & $68.67 \pm 8.32$ & 0.254 \\
\hline 50 minutes & $36 / 36$ & $64.94 \pm 7.71$ & $67.53 \pm 8.01$ & 0.168 \\
\hline 55 minutes & $36 / 36$ & $65.11 \pm 7.00$ & $67.78 \pm 8.35$ & 0.147 \\
\hline 60 minutes & $36 / 36$ & $65.83 \pm 7.12$ & $68.53 \pm 7.89$ & 0.133 \\
\hline 65 minutes & $36 / 36$ & $65.92 \pm 7.79$ & $68.83 \pm 8.08$ & 0.124 \\
\hline 70 minutes & $36 / 36$ & $66.14 \pm 8.39$ & $69.00 \pm 8.56$ & 0.157 \\
\hline 75 minutes & $36 / 36$ & $66.58 \pm 8.19$ & $69.67 \pm 9.03$ & 0.134 \\
\hline 80 minutes & $35 / 36$ & $66.91 \pm 7.44$ & $71.25 \pm 10.01$ & 0.043 \\
\hline 85 minutes & $35 / 34$ & $68.00 \pm 8.03$ & $73.62 \pm 9.62$ & 0.010 \\
\hline 90 minutes & $33 / 31$ & $68.76 \pm 8.70$ & $74.29 \pm 10.74$ & 0.027 \\
\hline 95 minutes & $30 / 28$ & $68.07 \pm 8.81$ & $74.29 \pm 11.59$ & 0.025 \\
\hline 100 minutes & $28 / 21$ & $67.93 \pm 16.46$ & $72.76 \pm 11.17$ & 0.252 \\
\hline 105 minutes & $28 / 19$ & $71.89 \pm 12.04$ & $76.74 \pm 12.05$ & 0.183 \\
\hline 110 minutes & $24 / 16$ & $69.33 \pm 8.97$ & $77.63 \pm 13.41$ & 0.024 \\
\hline 115 minutes & $21 / 13$ & $71.19 \pm 9.54$ & $78.62 \pm 13.45$ & 0.069 \\
\hline 120 minutes & $20 / 10$ & $74.40 \pm 8.79$ & $79.20 \pm 17.00$ & 0.313 \\
\hline 125 minutes & $15 / 6$ & $72.53 \pm 9.04$ & $82.50 \pm 20.71$ & 0.133 \\
\hline 130 minutes & $11 / 5$ & $71.73 \pm 9.00$ & $89.80 \pm 25.98$ & 0.053 \\
\hline 135 minutes & $10 / 3$ & $71.80 \pm 10.94$ & $84.00 \pm 17.08$ & 0.160 \\
\hline 140 minutes & $9 / 2$ & $72.78 \pm 12.03$ & $94.00 \pm 11.31$ & 0.049 \\
\hline 145 minutes & $8 / 2$ & $73.88 \pm 12.28$ & $95.50 \pm 7.77$ & 0.049 \\
\hline 150 minutes & $7 / 1$ & $77.14 \pm 14.34$ & 102.00 & 0.156 \\
\hline 155 minutes & $6 / 0$ & $78.50 \pm 16.38$ & 0 & - \\
\hline 160 minutes & $4 / 0$ & $77.50 \pm 19.07$ & 0 & - \\
\hline 165 minutes & $4 / 0$ & $86.50 \pm 33.48$ & 0 & - \\
\hline 170 minutes & $3 / 0$ & $72.00 \pm 15.10$ & 0 & - \\
\hline 175 minutes & $2 / 0$ & $74.50 \pm 21.92$ & 0 & - \\
\hline 180 minutes & $1 / 0$ & 68.00 & 0 & - \\
\hline 185 minutes & $1 / 0$ & 103.00 & 0 & - \\
\hline
\end{tabular}


Table 2: Comparison of mean arterial pressure in two groups at different timelines

\begin{tabular}{|c|c|c|c|c|}
\hline Timelines & $N$ group $D / P$ & Group D & Group P & pvalue \\
\hline Baseline & $36 / 36$ & $97.47 \pm 13.05$ & $93.42 \pm 10.87$ & 0.157 \\
\hline 5 minutes & $36 / 36$ & $87.25 \pm 15.68$ & $86.69 \pm 15.82$ & 0.882 \\
\hline 10 minutes & $36 / 36$ & $75.64 \pm 14.48$ & $80.69 \pm 14.61$ & 0.145 \\
\hline 15 minutes & $36 / 36$ & $74.47 \pm 17.43$ & $73.75 \pm 11.20$ & 0.835 \\
\hline 20 minutes & $36 / 36$ & $71.58 \pm 13.73$ & $68.39 \pm 7.59$ & 0.226 \\
\hline 25 minutes & $36 / 36$ & $69.78 \pm 11.61$ & $66.94 \pm 8.60$ & 0.244 \\
\hline 30 minutes & $36 / 36$ & $66.56 \pm 8.94$ & $65.28 \pm 6.63$ & 0.493 \\
\hline 35 minutes & $36 / 36$ & $65.39 \pm 8.13$ & $64.75 \pm 6.79$ & 0.719 \\
\hline 40 minutes & $36 / 36$ & $64.06 \pm 6.75$ & $63.89 \pm 8.01$ & 0.924 \\
\hline 45 minutes & $36 / 36$ & $64.36 \pm 6.99$ & $63.17 \pm 6.74$ & 0.463 \\
\hline 50 minutes & $36 / 36$ & $63.50 \pm 7.54$ & $63.50 \pm 7.22$ & 1.000 \\
\hline 55 minutes & $36 / 36$ & $63.94 \pm 7.05$ & $63.44 \pm 7.22$ & 0.767 \\
\hline 60 minutes & $36 / 36$ & $64.86 \pm 6.74$ & $64.42 \pm 8.97$ & 0.813 \\
\hline 65 minutes & $36 / 36$ & $64.81 \pm 7.01$ & $65.81 \pm 10.99$ & 0.647 \\
\hline 70 minutes & $36 / 36$ & $65.64 \pm 8.43$ & $66.75 \pm 9.05$ & 0.592 \\
\hline 75 minutes & $36 / 36$ & $66.08 \pm 8.63$ & $68.72 \pm 9.87$ & 0.231 \\
\hline 80 minutes & $35 / 36$ & $67.63 \pm 8.13$ & $69.78 \pm 10.53$ & 0.340 \\
\hline 85 minutes & $35 / 34$ & $69.31 \pm 10.04$ & $72.79 \pm 9.85$ & 0.151 \\
\hline 90 minutes & $33 / 31$ & $70.55 \pm 13.48$ & $76.00 \pm 12.00$ & 0.093 \\
\hline 95 minutes & $30 / 28$ & $70.37 \pm 11.88$ & $77.11 \pm 11.16$ & 0.030 \\
\hline 100 minutes & $28 / 21$ & $71.30 \pm 9.84$ & $74.90 \pm 12.31$ & 0.265 \\
\hline 105 minutes & $28 / 19$ & $72.30 \pm 10.62$ & $78.95 \pm 12.57$ & 0.059 \\
\hline 110 minutes & $24 / 16$ & $72.54 \pm 12.43$ & $80.88 \pm 13.45$ & 0.052 \\
\hline 115 minutes & $21 / 13$ & $74.05 \pm 10.99$ & $82.69 \pm 18.72$ & 0.098 \\
\hline 120 minutes & $20 / 10$ & $70.70 \pm 11.78$ & $80.50 \pm 10.77$ & 0.400 \\
\hline 125 minutes & $15 / 6$ & $73.93 \pm 9.91$ & $76.00 \pm 9.63$ & 0.669 \\
\hline 130 minutes & $11 / 5$ & $72.00 \pm 10.90$ & $77.20 \pm 10.28$ & 0.384 \\
\hline 135 minutes & $10 / 3$ & $72.80 \pm 11.90$ & $85.33 \pm 14.84$ & 0.156 \\
\hline 140 minutes & $9 / 2$ & $74.56 \pm 12.16$ & $88.00 \pm 1.41$ & 0.168 \\
\hline 145 minutes & $8 / 2$ & $76.63 \pm 12.44$ & 78.00 & 0.920 \\
\hline 150 minutes & $7 / 1$ & $79.86 \pm 12.15$ & 80.00 & 0.992 \\
\hline 155 minutes & $6 / 0$ & $81.50 \pm 11.50$ & 0 & - \\
\hline 160 minutes & $4 / 0$ & $89.75 \pm 22.02$ & 0 & - \\
\hline 165 minutes & $4 / 0$ & $88.50 \pm 15.92$ & 0 & - \\
\hline 170 minutes & $3 / 0$ & $78.67 \pm 12.66$ & 0 & - \\
\hline 175 minutes & $2 / 0$ & $72.00 \pm 1.41$ & 0 & - \\
\hline 180 minutes & $1 / 0$ & 56.0 & 0 & - \\
\hline 185 minutes & $1 / 0$ & 80.0 & 0 & - \\
\hline
\end{tabular}

Table 3: Comparison of initial and average infusion rate in two groups

\begin{tabular}{lll}
\hline Infusion rate & Group $D$ & Group $P$ \\
\hline Initial & $17.44 \pm 5.05 \mu \mathrm{g} /$ hour & $129.17 \pm 39.08 \mathrm{mg} /$ hour \\
Average & $12.11 \pm 3.46 \mu \mathrm{g} /$ hour & $88.33 \pm 30.61 \mathrm{mg} /$ hour \\
\hline
\end{tabular}

Table 4: Comparison of Ramsay sedation score in two groups

\begin{tabular}{llll}
\hline Parameter & Group D & Group $P$ & pvalue \\
\hline Ramsay sedation score & $2.19 \pm 0.40$ & $3.06 \pm 0.67$ & $<0.0001$ \\
\hline
\end{tabular}

Mean Ramsay sedation score was $2.19 \pm 0.40$ in group $D$ patients which was significantly lower ( $p$ value $<0.0001$ ) when compared to group P score which was $3.06 \pm 0.67$ as shown in Table 4 .
Table 5: Postoperative awake time in two groups

\begin{tabular}{llll}
\hline Parameter & Group D & Group P & p value \\
\hline Post-op awake time $(\mathrm{min})$ & $16.42 \pm 4.40$ & $20.33 \pm 4.81$ & 0.001 \\
\hline
\end{tabular}

In our study, postoperative awakening time is the time from stopping of hypotensive agent infusion for awakening of patient after reversal of neuromuscular blockade.

Table 5 shows that postoperative awake time was significantly less in group D than group P $(16.42 \pm 4.40$ vs $20.33 \pm 4.81$ respectively, $p$ value $=0.001$ )

\section{Discussion}

The deliberate reduction of blood pressure in an attempt to reduce intraoperative blood loss has generated controversy since its clinical 
introduction. ${ }^{14}$ However, nowadays the technique is used routinely in various surgeries including those of ENT.14,15 In our study, we compared dexmedetomidine and propofol for achieving controlled hypotension in ENT surgeries.

In our study, there is no significant difference in the two groups in mean age ( $p$ value $=0.662)$ and gender ( $p$ value $=$ 0.346). Similar studies by Shah and Kulkarni ${ }^{11}$ and Moshiri et al. ${ }^{10}$ reported no significant difference in mean age and gender in the two groups. There is no significant difference in BMI in the two groups in our study. Verma et al. ${ }^{13}$ and Shah and Kulkarni ${ }^{11}$ also reported no significant difference in $\mathrm{BMI}$ in their studies. In group $D$, there was decrease in the HR during and after the intravenous bolus dose of dexmedetomidine with rise in BP which settled down within 10 minutes after induction and starting infusion. The transient hypertensive response is due to the initial stimulation of $a-2 B$ receptors in the vascular smooth muscles. The bradycardia is attributed to reflex response for the transient hypertension. This hypertensive episode settles down with the decrease in the central sympathetic outflow. The subsequent decrease in the HR is also because of decreased central sympathetic outflow. ${ }^{16}$ The HR was lower in both the groups when compared to the baseline HR. There was no statistical difference in HR until 80 minutes after induction. Thereafter, transient increase in HR was observed in propofol group. There were no statistically significant differences in mean HR in the two groups intraoperatively, but the HR was lower in group D than group P. Shah and Kulkarni have reported statistically significant lowering in the HR in both the groups from 4 minutes after induction. ${ }^{11}$ There were no cases of bradycardia in both the groups in our study, but it has been reported in some studies. ${ }^{10,11,17}$ Moshiri et al. reported significant decrease in HR in both the groups with significant lowering in propofol group. ${ }^{10}$

Mean SBP, DBP, and MAP at baseline did not differ in both the groups. Five minutes after starting the infusion SBP, DBP and MAP started reducing and settled down in the desired range. There was no statistically significant difference in SBP, DBP, and MAP in both the groups, although all the pressures were high in the propofol group. Varma et al. reported significant lowering in MAP in the propofol group. They found hypotension in 2 cases of dexmedetomidine group and 10 cases in propofol group which was treated with intravenous fluids. ${ }^{13}$ Shah and Kulkarni reported statistically significant lowering in MAP in the dexmedetomidine group. Three patients in dexmedetomidine and 2 in propofol group developed hypotension. ${ }^{11}$ Moshiri et al. reported no statistically significant difference in MAP in both the groups. ${ }^{10}$

In our study, we started dexmedetomidine infusion at the rate of $0.2-0.7 \mu \mathrm{g} / \mathrm{kg} /$ hour after the bolus of $1 \mu \mathrm{g} / \mathrm{kg}$ diluted in saline which was given over 10 minutes before induction. Then, the rate of infusion was titrated to achieve the desired level of MAP between 55 and $65 \mathrm{~mm} \mathrm{Hg}$ with stable hemodynamics. The average infusion rate of dexmedetomidine in our study was 12.11 $\pm 3.46 \mu \mathrm{g} / \mathrm{hour}$ that is $0.2 \pm 0.04 \mu \mathrm{g} / \mathrm{kg} / \mathrm{hour}$ which is at the lowest of the recommended range of $0.2-0.7 \mu \mathrm{g} / \mathrm{kg} / \mathrm{hour}$. The average infusion rate of propofol was $88.33 \pm 30.61 \mathrm{mg} /$ hour which comes to around $140 \pm 42 \mu \mathrm{g} / \mathrm{kg} / \mathrm{hour}$.

Verma et al. compared dexmedetomidine and propofol for middle ear surgeries done under local anesthesia and sedation. They used $1 \mu \mathrm{g} / \mathrm{kg}$ dexmedetomidine bolus followed by $0.4 \mu \mathrm{g} /$ $\mathrm{kg} /$ hour infusion. Propofol $75 \mu \mathrm{g} / \mathrm{kg} /$ minute bolus was followed by $50 \mu \mathrm{g} / \mathrm{kg} /$ minute infusion. The surgical field and hemodynamic stability were good in the dexmedetomidine group. ${ }^{13}$ Moshiri et al. compared dexmedetomidine and propofol for functional endoscopic sinus surgery. Dexmedetomidine $1 \mu \mathrm{g} / \mathrm{kg}$ bolus was followed by $0.4-0.8 \mu \mathrm{g} / \mathrm{kg} / \mathrm{hour}$ infusion. Propofol infusion was used in the dose of $50-150 \mu \mathrm{g} / \mathrm{kg} /$ minute. They reported comparable MAP and surgical field in both the groups. ${ }^{10}$ Shah et al. compared dexmedetomidine and propofol for FESS. They used dexmedetomidine $0.5 \mu \mathrm{g} / \mathrm{kg} /$ hour infusion and propofol $100 \mu \mathrm{g} / \mathrm{kg} /$ hour infusion. They reported good surgical field, less blood loss, and better control of HR in dexmedetomidine group. ${ }^{11}$ Farah Nasreen et al. used dexmedetomidine for middle ear surgeries with $1 \mu \mathrm{g} / \mathrm{kg}$ bolus followed by $0.4 \mu \mathrm{g} / \mathrm{kg} /$ hour infusion. They did not report HR less than 50/minute or hypotension, where anticholinergic drugs or vasopressors were required. ${ }^{18}$

Neamat et al. used two different doses of dexmedetomidine for hypotensive anesthesia during FESS. They gave $1 \mu \mathrm{g} / \mathrm{kg}$ bolus in both the groups followed by $0.4 \mu \mathrm{g} / \mathrm{kg} /$ hour infusion in one group and $0.8 \mu \mathrm{g} / \mathrm{kg}$ infusion in the other group. They reported best hemodynamic stability in $0.8 \mu \mathrm{g} / \mathrm{kg} / \mathrm{hour}$ dexmedetomidine infusion group. ${ }^{19}$ Bharathwaj et al. compared dexmedetomidine and propofol for FESS. They used dexmedetomidine $0.5 \mu \mathrm{g} / \mathrm{kg}$ bolus followed by $0.3 \mu \mathrm{g} / \mathrm{kg} / \mathrm{hour}$ infusion and propofol $12 \mathrm{mg} /$ $\mathrm{kg} /$ hour for first 10 minutes, $10 \mathrm{mg} / \mathrm{kg} /$ hour for next 10 minutes, and $8 \mathrm{mg} / \mathrm{kg} /$ hour for rest of the surgery. They reported both drugs to be good and efficacious and both provide ideal surgical conditions and hemodynamic stability with hypotensive anesthesia and reduced blood loss during surgery. Dexmedetomidine is comparatively better in controlling HR, BP, and blood loss. ${ }^{20}$ Rayan et al. used dexmedetomidine for FESS. They used new protocol. They used dexmedetomidine $1 \mu \mathrm{g} / \mathrm{kg}$ bolus followed by $0.2-0.7$ $\mu \mathrm{g} / \mathrm{kg} / \mathrm{hour}$ infusion in group I and $1 \mu \mathrm{g} / \mathrm{kg}$ bolus followed by $1 / 4$ dose of the bolus as bolus doses over 2 minutes to maintain MAP between 65 and $70 \mathrm{~mm} \mathrm{Hg}$ in the second group. In the second group consumption of dexmedetomidine was less, and the emergence time was 5.34 minutes compared to 9.45 minutes in the first group and modified Aldrete score was good. ${ }^{21}$ Das et al. compared dexmedetomidine $1 \mu \mathrm{g} / \mathrm{kg}$ bolus and clonidine $1.5 \mu \mathrm{g} / \mathrm{kg}$ bolus preoperatively for hypotensive anesthesia in FESS surgeries. They reported hypotension and bradycardia in clonidine group and better hemodynamic stability in dexmedetomidine group. ${ }^{22}$

Rehab SEI-Kalla et al. compared dexmedetomidine and sodium nitroprusside (SNP) for hypotensive anesthesia in maxillofacial surgeries. They used dexmedetomidine $1 \mu \mathrm{g} / \mathrm{kg}$ bolus followed by $0.2-0.5 \mu \mathrm{g} / \mathrm{kg} / \mathrm{hour}$ infusion and SNP $0.25 \mathrm{mg} / \mathrm{kg} / \mathrm{minute}$ infusion. They reported dexmedetomidine to be a better drug for hemodynamic stability. ${ }^{23}$ Gupta et al. used dexmedetomidine infusion $0.5 \mu \mathrm{g} / \mathrm{kg} / \mathrm{hour}$ for hypotensive anesthesia in middle ear surgeries. No bolus dose was used. They reported good surgical field with dexmedetomidine. ${ }^{24}$

Shams et al. compared esmolol $1 \mathrm{mg} / \mathrm{kg}$ bolus followed by $0.4-0.8 \mathrm{mg} / \mathrm{kg} / \mathrm{hour}$ and dexmedetomidine $1 \mu \mathrm{g} / \mathrm{kg}$ bolus followed by $0.4-0.8 \mu \mathrm{g} / \mathrm{kg} / \mathrm{hour}$ infusion for inducing hypotensive anesthesia for FESS. They reported both the agents to be safe and effective hypotensive agents. Dexmedetomidine has inherent analgesic, anesthetic-sparing, and sedative properties. Emergence time was long in dexmedetomidine group compared to esmolol group. ${ }^{25}$

The postoperative awakening time, that is the time from switching off the drug infusion to emergence from anesthesia and extubation in our study, is $16.42 \pm 4.40$ minutes in dexmedetomidine group and $20.33 \pm 4.81$ minutes in propofol group. We have switched off the infusion 10 minutes before the end of surgery 
in all our patients. So, the emergence time in group $D$ is $6.42 \pm$ 4.40 minutes and $10.33 \pm 4.81$ minutes. Thus, the postoperative awakening time is significantly less in group $D$ than group $\mathrm{P}(p$ value $=0.001)$. In a study, awakening time was $9.1 \pm 2.7$ minutes. ${ }^{17}$ Rayan et al. have reported the emergence time of 9.45 minutes in dexmedetomidine infusion group and 5.34 minutes in the group in which dexmedetomidine boluses were used. The short emergence time in our study might be due to lower average dose of dexmedetomidine and propofol in the Indian population.

Ramsay sedation score achieved in group D was significantly lower than group $\mathrm{P}(2.19 \pm 0.40$ vs $3.06 \pm 0.67, p$ value $<0.0001)$. This score precisely provides the level of consciousness during titration of sedative medication. ${ }^{26}$ A lower score in dexmedetomidine group suggests that patients were not under deep sedation compared to propofol which helps in early postoperative recovery. This is supported by longer postoperative awakening time in propofol group. Farah Nasreen et al. have also used Ramsay sedation scale in their study. Ramsay sedation score was high in $0.8 \mu \mathrm{g} / \mathrm{kg} / \mathrm{hour}$ dexmedetomidine group compared to $0.4 \mathrm{\mu g} / \mathrm{kg} /$ hour group. $^{17}$ Moshiri et al. reported no significant difference in time to extubation or recovery in either groups. ${ }^{10}$

In our study, we did not have hypotension or bradycardia which needed treatment. The HR and and BP were on the lower side in group D compared to group P. The awakening time was significantly short in group $D$ than group P. No patient from both the groups had nausea and vomiting. The postoperative analgesic requirements were less in group $\mathrm{D}$. The average doses of dexmedetomidine around $0.2 \pm 0.04 \mu \mathrm{g} / \mathrm{kg} / \mathrm{hour}$ and propofol around $140 \pm 41 \mu \mathrm{g} / \mathrm{kg} / \mathrm{hour}$ which are at the lowest end of the recommended doses of 0.2-0.7 $\mu \mathrm{g} / \mathrm{kg} /$ hour and $100-300 \mu \mathrm{g} / \mathrm{kg} /$ hour for hypotensive anesthesia. ${ }^{4,27}$ These low doses may be the cause of no complications in the Indian population in our study.

\section{Conclusion}

As per our study design, both dexmedetomidine and propofol could achieve desired hypotension without any complications in patients undergoing ENT surgeries with submaximal doses in the Indian population. We did not have any complications because of the collective effects of upper head tilt position, use of fentanyl, sevoflurane, and infusion of submaximal doses of dexmedetomidine or propofol. We feel dexmedetomidine is better drug in maintaining hemodynamic stability than propofol during hypotensive anesthesia in ENT surgeries. The lower Ramsay score in dexmedetomidine group suggests fast emergence from anesthesia and early postoperative recovery. As per our study design, dexmedetomidine is a better drug for hypotensive anesthesia per the surgeon's satisfaction owing to good surgical field and less blood loss.

\section{References}

1. Degoute CS. Controlled hypotension: a guide to drug choice. Drugs 2007;67(7):1053-1076. DOI: 10.2165/00003495-20076707000007.

2. Degoute CS, Roy MJ, Manchon M, et al. Remifentanyl and controlled hypotension; comparison with nitroprusside or esmolol during tympanoplasty. Can J Anaesth 2001;48(1):20-27. DOI: 10.1007/ BF03019809.

3. Naaz S, Ozalr E. Dexmedetomidine in current anesthesia practice: a review. J Clin Diagn Res 8(10):GE01-GE04. DOI: 10.7860/ JCDR/2014/9624.4946.
4. Kaur M, Singh PM. Current role of dexmedetomidine in clinical anesthesia and intensive care. Anesth Essays Res 2011;5(2):128-133. DOI: 10.4103/0259-1162.94750.

5. McCallum JB, Boban N, Hogan Q, et al. The mechanism of a2 adrenergic inhibition of sympathetic ganglionic transmission. Anesth Analg 1998;87(3):503-510. DOI: 10.1097/00000539-199809000-00001.

6. Guo TZ, Jiang JY, Buttermann AE, et al. Dexmedetomidine injection into the locus coeruleus produces antinociception. Anesthesiology 1996;84(4):873-881. DOI: 10.1097/00000542-199604000-00015.

7. Deegan RJ. Propofol:A review of the pharmacology and applications of an intravenous anaesthetic agent. Am J Med Sci 1992;304(1):45-47. DOI: 10.1097/00000441-199207000-00012.

8. Trapani G, Altomare C, Liso G, et al. Propofol in anesthesia. Mechanism of action structure activity relationship, and drug delivery. Curr Med Chem 2000;7(2):249-271. DOI: 10.2174/0929867003375335.

9. Boonmak P, Boonmak S, Laopaiboon M. Deliberate hypotension with propofol under anesthesia for functional endoscopic sinus surgery (FESS). Cochrane Database Syst Rev 2013;6(6):CD006623.

10. Moshiri E, Modir H, Yazdi B, et al. Comparison of the effects of propofol and dexmedetomidine on controlled hypotension and bleeding during endoscopic sinus surgery. Ann Trop Med Public Health 2017;10(3):721-725.

11. Shah $\mathrm{H}$, Kulkarni A. A comparative study between dexmedetomidine infusion and propofol infusion for maintenance in patients undergoing functional endoscopic sinus surgery under general anesthesia. IOSR J Dent Med Sci 2016;15(3):82-86.

12. Rupa Kumari A, Upendranath I, Sigh DB, et al. Dexmedetomidine vs propofol and fentanyl for controlled hypotensive anesthesia in functional endoscopic sinus surgery. Evid Based Med Healthc 2015;2(36):5782-5792. DOI: 10.18410/jebmh/2015/794.

13. Verma R, Gupta R, Bhatia VK, et al. Dexmedetomidine and propofol for monitored anesthesia care in the middle ear surgery. Indian J Otol 2014;20(2):70-74.

14. Ward CF, Alfery DD, Saidman LJ, et al. Deliberate hypotension in head and neck surgery. Head Neck Surgery 1980;2(3):185-195. DOI: 10.1002/hed.2890020304.

15. Condon HA. Deliberate hypotension in ENT surgery. Clin Otolaryngol Allied Sci 1979;4(4):241-246.

16. Sudheesh K, Harsoor SS. Dexmedetomidine in anesthesia practice: a wonderful drug? Indian J Anaesth 2011;55(4):323-324. DOI: 10.4103/0019-5049.84824.

17. Basar H, Akpinar S, Doganci N, et al. The efficacy of preanaesthetic single dose dexmedetomidine on induction, hemodynamic and CVS parameters. J Clin Anesth 2008;20(6):431-436. DOI: 10.1016/j. jclinane.2008.04.007.

18. Nasreen F, Bano S, Khan RM, et al. Dexmedetomidine used to provide hypotensive anesthesia during middle ear surgery. Indian J Otolaryngol Head Neck Surg 2009;61(3):2005-2207. DOI: 10.1007/ s12070-009-0067-8.

19. Abel Rahman NI, Fouad EA, Ahmad A, et al. Efficiency of different dexmedetomidine regimens in producing controlled hypotensive anesthesia during functional endoscopic sinus surgery. Egypt J Anaesth 2014;30(4):339-345. DOI: 10.1016/j.egja.2014.04.001.

20. Bharathwaj DK, Kmath SS. Comparison of dexmedetomidine vs propofol-based anesthesia for controlled hypotension in functional endoscopic sinus surgery. South Afr J Anaesth Analg 2018. DOI: 10.1080/22201181.2018.1517484.

21. Rayan AA. Controlled hypotensive anesthesia for functional endoscopic sinus surgery: dexmedetomidine a new protocol for administration. Ain-Shams J Anesthesy 2016;9(1):57-65. DOI: 10.4103/1687-7934.178881.

22. Das A, Mukherjee A, Chhaule $S$, et al. Induced hypotension in ambulatory functional endoscopic sinus surgery: a comparison between dexmedetomidine and clonidine as premedication. A prospective, double-blind and randomized study. Saudi J of Anaesth 2016;10(1):74-80. DOI: 10.4103/1658-354X.169480.

23. El-Kalla RS, El Mourad MB. Deliberate 23. Rehab hypotensive anesthesia during maxillofacial surgery: a comparative study 
between dexmedetomidine and sodium nitroprusside. Ains-Shams J Anesth 2016;9(2):201-206.

24. Gupta K, Bansal M, Gupta PK, et al. Dexmedetomidine infusion during middle ear surgery under general anesthesia to provide oligaemic surgical field: a prospective study. Indian J Anaesth 2015;59(1):26-30.

25. Shams T, Bahnasawe NSEl, Abu-samra M, et al. Induced hypotension for functional endoscopic sinus surgery: a comparative study of dexmedetomidine vs esmolol. Saudi J Anaesth 2013;7(2):175-180 DOI: 10.4103/1658-354X.114073.

26. Ramsay Sedation Scale-an overview|Science Direct Topic. https:// www.sciencedirect.com>topics.

27. Robert K. Stoelting. Pharmacology and Physiology in Anesthesia Practice. 3rd edn, Philadelphia, Pennsylvania: Lippincott-Raven Publishers; 1999. p. 140-145. 